Withdrawn, strong, kind, but de-gendered: Non-disabled South Africans' stereotypes concerning persons with physical disabilities

\title{
Authors:
}

Xanthe Hunt, Department of Psychology, Stellenbosch University, South Africa Mark Carew, Leonard Cheshire Research Centre, UCL, London

Stine Hellum Braathen, Department of Health Research, SINTEF Technology and Society, Norway

Leslie Swartz, Department of Psychology, Stellenbosch University, South Africa Mussa Chiwaula, Southern African Federation of the Disabled, Botswana Poul Rohleder, School of Psychology, University of East London, UK

Accepted 23 May 2018 for publication in Disability and Society This article may not exactly replicate the final version published in the journal 


\section{Withdrawn, strong, kind, but de-gendered: Non-disabled South Africans' stereotypes concerning persons with physical disabilities}

\section{Background}

Stereotypes, readers of this journal well know, are sets of qualities which people are assumed to share based on their perceived or real membership to a social category (Ashmore \& Del Boca, 1981). When applied to others we perceive different to ourselves, stereotypes morph into images of personhood we expect those others to enact. Functionally, stereotypes create expectations and beliefs which hold with remarkable endurance (Foddy, Platow, \& Yamagishi, 2009; Kao, 2000; Tiedens, Ellsworth, \& Mesquita, 2000).

When applied to marginalised groups, stereotypes can cause harm (via prejudice). When held by the majority, stereotypical images of marginalised persons often have problematic implications for the latter group, perpetuating their marginalisation (Hubbard, 1998; Manthorpe, Bowes, Innes, Archibald, \& Murphy, 2004). This, we suggest, is the case for people with disabilities (PWD).

PWD have often been the subject of a number of problematic stereotypes held by non-disabled people. One such stereotype, most often applied to people with physical disabilities (PWPD), is that they lack sexuality. Some work seems to support the claim that PWPD are seen as less sexual than non-disabled people (NarioRedmond, 2010); however, no research has yet examined stereotyping in relation to physical disability ${ }^{1}$ and gender in the Global South, a context in which, for reasons discussed presently, such stereotypes might have dire consequences for PWPD (especially women). The present paper sets out to address this gap by reporting findings from a large survey of stereotypes about PWPD and gender, conducted amongst non-disabled people in South Africa.

\footnotetext{
${ }^{1}$ There is debate in the field of disability studies over the terminology by which people with impairments are referred to. In this article, we employ 'person first' language, where, conceptually, personhood is given primacy over disability identity, hence, 'person with a physical disability' (this derives from an American school of thought). There are scholars, however, who prefer the term 'disabled people', in order to recognise and value disability identity (this derives from the Social Model school of thought). The former terminology was selected to make the article coherent. We also use the term 'disability' over the word 'impairment', in acknowledgment of the social model, and its emphasis on disablement as a social process (which is of relevance to the present inquiry).
} 


\section{Concerning stereotypes}

The study of disability as a social construct began in the 1940s (Asch \& McCarthy, 2003). In this work, disability is examined as a group categorisation based on homogenising representations applied consistently by the majority of society to PWD (Asch \& McCarthy, 2003). Such representations are stereotypes which are used as a social heuristic to define groups in ways which distinguish them from others (McCauley \& Stitt, 1978).

Recent work by Dixon (2017) deftly elaborates the manner in which claims about stereotype inaccuracy have led scholars to falsely dismiss all stereotypes as problematic. Some stereotypes, however, are derived from fact, and Dixon (2017) argues that 'accepting that groups differ, and that their differences are often validly perceived by members of a society, is a necessary first step on the path to social justice'. Dixon (2017) presciently argues for a shift in how the relationship between stereotyping and social perception is interpreted - an examination of how our construction of social reality is produced by interactions with the world out there, and our internal meaning-making systems 'in here', rather than attempting to quantify whether what we may believe about others is justified. In critical disability studies there is an important position taken in challenging stereotypes about 'vulnerability' or 'capacity' or 'dependency'. What Dixon's (2017) work does allude to is that this does not mean that these stereotypes are necessarily baseless, for some PWD these issues may be areas of concern or actual experience.

In the vein of Dixon (2017), we do not assume that all stereotypes are inaccurate, nor entirely distorted. We have evidence that some are inaccurate, and that nondisabled people are invested in the pervasiveness of this inaccuracy. We also suggest that some stereotypes create a performative expectation for PWD, which may lead to a cyclical reification and enactment of the stereotype by non-disabled people and PWD, respectively. In line with Dixon (2017), we work from the perspective that 'stereotyping is not a matter of (mis)perceiving or (mis)representing the already existing qualities of individuals or groups. Rather, it is a matter of actively constructing those qualities and indeed the very nature of social categories that are deemed applicable within a given context' $(2017,18)$. However, we take a political 
line in emphasising the characteristics of disablist dynamics which hold problematic constructions - often inaccurate - in place.

Arguments regarding the function or accuracy of stereotypes aside, we do know that stereotypes concerning PWD exist. Researchers have attempted to understand stereotyping in relation to persons with disabilities by establishing whether disabled people are viewed in consistent ways (Nario-Redmond, 2010). This research is based on the premise that, while most people hold a unique set of personal beliefs and frame of reference for understanding social groups, these views and beliefs are often influenced by socialisation and so reflect broader cultural stereotypes. Thus, consistency amongst individual views and beliefs reveals the nature of cultural stereotypes (Schneider, 2005). What studies in this area have revealed is that such stereotypes do exist (Abrams, Jackson, \& St Claire, 1990; Braathen \& Ingstad, 2006; Coleman et al., 2015; Fiske, Cuddy, Glick, \& Xu, 2002; Hanass-Hancock, 2009; Kvam \& Braathen, 2008; Maras \& Brown, 1996).

Regarding PWPD in particular, cultural studies work has examined how PWPD have been portrayed using certain tropes or stereotypes. These include the PWPD as Freak (Garland-Thomson, 2009), the medical anomaly (Condrau, 2007; GarlandThomson, 2009; Reeve, 2012), and the inspiration or SuperCrip (Grue, 2016; Shakespeare, 1994).

Indirect evidence of stereotypes of PWPD can be gleaned from other sources, not least of which the reports of PWPD themselves. In a study by Crawford and Ostrove (2003), women with physical disabilities (WWPD) noted encountering beliefs from non-disabled others which characterised PWPD as 'universally intellectually challenged', lacking sexuality, helpless, and incompetent (Crawford \& Ostrove, 2003, 186). Similar findings were reported by Kvam and Braathen (2008) and Braathen and Ingstad (2006).

To date, work involving the direct measurement of disability stereotypes is scarce in the Global South. This despite the fact that research on the homogenising ways of thinking about PWD would make a notable contribution to our knowledge of the underpinnings of attitudes towards PWD in contexts outside of the Global North 
(recent work by the authors has noted the importance of examining possible antecedents of attitudes towards PWPD) (see Author et al., 2018).

In the sections which follow, we will outline why this tendency to draw on stereotypes to guide social expectations is of particular import for thinking about stereotypes concerning disability - particularly, stereotypes concerning physical disability and sexuality, and gender.

\section{Concerning attitudes towards PWPD}

As Sechrist and Stangor (2001) note, identifying the contents of societal stereotypes is important as this content influences when and how the stereotypes are used, with far-reaching consequences for those who are stereotyped. An individual without disability's awareness of societal stereotypes can influence their reactions to PWPD in stereotype-congruent ways (Bargh, 1999). In the case of sexuality, as Wood and Nario-Redmond (cited in Nario-Redmond, 2010) note, stereotypical representations of PWPD as lacking sexuality can influence perceptions, judgements and expectations for PWPD amongst people without disability, even when the latter discredit the veracity of the stereotypes (Crawford \& Ostrove, 2003).

Problematic attitudes towards PWPD, particularly as pertains to their gender, sexuality, and suitability as romantic partners, are prevalent (Hergenrather \& Rhodes, 2007; Marini, Chan, Feist, \& Flores-Torres, 2011; Miller, Chen, Glover-Graf, \& Kranz, 2009). It appears that some of this is due to negative social constructions and stereotypes concerning PWPD. However, in general, and in the Global South in particular, we lack evidence of these stereotypes. In the section which follows, we will briefly discuss the necessity of such work, particularly in South Africa, and why an examination of stereotypes concerning PWPD should also incorporate gender.

\section{Concerning gender and disability}

Usually, gender is a primary marker of identity, one of the first features of a person which meet our attention in interaction with them. It is thus one of the first features of a person which would be subject to our deployment of stereotypes in interaction with them. 
According to writers such as Rich (2014), however, disability is an identity which supersedes gender (Goffman 1959). As gender roles are enacted through the performance of certain activities, activities which disability may make impossible (either in reality, or in the eyes of others), disability can 'trump' a PWD's gender identity in the eyes of others (Banks, 2010), the former working to negate the latter (in the eyes of society at large).

Past work has shown that PWD are characterised as less sexual than non-disabled people, and unattractive (Nario-Redmond, 2010). In essence, the stereotypes concerning PWD appeared to exist in direct opposition to the traditional characteristics of their respective gender group (Schlesinger, 1996; Tilley, 1996).

In South Africa, there is reason to believe that the intersection of gender and disability stereotypes has particularly dire consequences for women with disabilities. In the KwaZulu-Natal province, Hanass-Hancock (2009) notes that disability and gender are both associated with myths and stereotypes that exacerbate the vulnerability of PWD to HIV/AIDS, particularly women. The prevalent idea that PWD are lacking sexuality, virgins, sexually overactive, cursed, dirty or clean, all contribute to their vulnerability to sexual abuse and, subsequently, HIV/AIDS in this context (Hanass-Hancock, 2009).

Over and above risk of abuse and HIV, intersections between gender and disability stereotypes mean that WWPD in particular are seen as unable to fulfil traditional roles, and are liable to be seen as 'lucky' if a person without disability 'sees fit' to have sex with them, regardless of their own desire (Kvam \& Braathen, 2008).

When these three strands of thinking are taken together, the relevance of examining societal stereotypes concerning men and WWPD becomes apparent: stereotypes are likely to be desexualising or at least de-gendering for PWPD; stereotypes guide attitudes; desexualising attitudes, when encountered by PWPD, are harmful.

\section{Concerning stereotypes of sexuality and disability}

Stereotypes about PWPD which appear to be particularly prevalent, are those which concern their sexuality - or, rather, characterise PWPD as lacking sexuality. In 
relation to disability and sexuality specifically, Nario-Redmond (2010) elicited students' stereotypes regarding men and women with disabilities, and contrasted them with stereotypes regarding non-disabled men and women. Only non-disabled women and men were stereotyped along traditional gender lines, whereas persons with disabilities were characterised as asexual and unattractive (Nario-Redmond, 2010). Traditional male and female gender stereotypes were found only for nondisabled targets, and the stereotypes of male and female targets with disabilities were characterised as more similar to one another, and, overall, as less gendered. Further, men and women with disabilities were seen as uniformly dependent, incompetent, and asexual (Nario-Redmond, 2010). This buttresses the point, made earlier, that common myths relating to PWPD are constructed in opposition to the traditional gender characteristics of a group (Schlesinger, 1996; Tilley, 1996).

Nguyen, Liamputtong, and Monfries (2016) noted that stereotypes about physical disability resulted in a lack of knowledge about reproductive health of PWPD, and that PWPD, especially women, faced stigmatising stereotypes which portrayed them as asexual, de-gendered, unattractive, and unsuitable for motherhood.

The above work has important implications for considering how non-disabled people may think and feel about the sexuality of PWPD. Stereotypical representations of PWPD as asexual can influence the perceptions, judgements and expectations of PWD, even amongst non-disabled participants who discredit the veracity of the stereotypes themselves (Coleman et al., 2015; Nario-Redmond, 2010; Wood \& Nario-Redmond cited in Nario-Redmond, 2010). For instance, as Nario-Redmond (2009) explains, non-disabled people who do not actively express the assumption that WWPD are not sexually active, might still be surprised to discover that a woman with a physical disability has a child.

PWPD have been very widely argued to be subject to rigid and relatively unremitting processes of desexualisation by society at large. This desexualisation, the literature suggests, is sustained by stereotypes which characterise PWPD as infantile, dependent and 'de-gendered'. 
By examining the stereotypes which a sample of non-disabled South Africans employ in describing PWPD, we hope to shed light on how such stereotypes might contribute to some of the problematic attitudes and sequelae of attitudes encountered by PWPD.

\section{Method}

\section{Participants and procedure}

Cross-sectional data for the present study were gathered using an online survey examining the attitudes of people without disability towards different facets of sexuality and disability. The survey (hosted on Qualtrics) contained two free response items. The survey was translated into three South African languages isiXhosa, isiZulu, and Afrikaans ${ }^{2}$ - and participants could choose to respond in any of these languages, or in English. The survey was advertised on social media, as well as on two prominent South African online news sites. ${ }^{3}$ We obtained permission from the institutional planning departments of two large urban universities, one in the Western Cape and one in Gauteng, to advertise the survey amongst their students. The survey was also administered by hand by trained data collectors in Langa and Khayelitsha, ${ }^{4}$ two large peri-urban settlements in the Western Cape. The pen-andpaper survey participants were selected at convenience by the data collectors, who were residents of the areas in question. Due to the sexual nature of some of the items in the questionnaire, all participants had to be at least 18 years old to be included in the study. After five months, the survey was closed, the pen-and-paper collection finished, and the qualitative data entered into Atlas.ti. ${ }^{5}$

\section{Materials}

The survey included questions measuring attitudes towards different facets of physical disability and sexuality, as well as a demographic questionnaire (findings from the quantitative data produced by these items will be published elsewhere, see Author et al., in press). In the introduction to the survey, a PWPD was defined as

\footnotetext{
${ }^{2}$ isiXhosa and isiZulu are two of South Africa's 11 official languages. These indigenous languages are spoken mostly by Black South Africans. isiXhosa is the home language of $22.7 \%$ of the population, and isiZulu, $16 \%$, making them the two largest language groups in the country. Afrikaans is the home language of $13.5 \%$ of the population, making it the third largest language group in the country (Statistics South Africa, 2011).

${ }^{3}$ The Sowetan and Timeslive.

${ }^{4}$ Langa and Khayelitsha are two large, peri-urban settlements on the outskirts of Cape Town in South Africa. Their inhabitants are largely Black African and Xhosa-speaking.

${ }^{5}$ ATLAS.ti is a computer programme used in qualitative data analysis. For more details, see http://atlasti.com/product/
} 
'someone with a physical impairment that has a substantial and long term adverse effect on the person's ability to perform normal day to day activities e.g. walking, eating, going shopping' (Government of United Kingdom, 2010). As part of this survey, we assessed stereotypes using free-response items.

\section{Free response analysis}

Free-response items are based in a free association technique which elicits participants' spontaneously-activated traits in relation to a target group. The questions request participants to state three traits that come to mind when thinking of men who have physical disabilities, and three which come to mind when thinking of women who have physical disabilities.

This methodology has been used in previous research into attitudes towards men and women with disabilities (Nario-Redmond, 2010). In the present study, freeresponses were limited to three descriptive points per target, per respondent, based on recommendations from prior research (Nario-Redmond, 2010; Niemann, Jennings, Rozelle, Baxter, \& Sullivan, 1994).

\section{Analysis}

The data for the free response questions were imported into Atlas.ti. Responses were then coded by two research assistants on the project, as well as the first author. During this process, the three traits listed by each respondent in each item were assigned a homonymous code. If a response was longer than one word, for instance, 'physically limited' or 'less than they could have been', then, for ease of analysis, the coders assigned it a synonymous, single- or two-word code. Codes were kept separately by gender.

We coded the responses until saturation was reached, and no new traits were emerging. The first author then randomly selected a sample of the remaining questionnaires, checking whether these responses contained any novel traits. They did not. In the final code lists, there were 598 codes (traits) for male targets, and 546 codes (traits) for female targets. Each code corresponded to a trait. All frequencies spoken about in the sections which follow are expressed as a percentage of the total number of the total responses for a gender. 
We first calculated the relative frequencies for each individual trait. We then clustered the traits, with their associated frequencies, into stereotypes. In a manner similar to the formation of themes in thematic analysis, this process entailed the categorisation of codes into larger, discrete groups which encapsulated something novel about the data, in this case, novel images of PWPD. We then calculated the rank of each stereotype, by summing the frequencies of traits associated with it. We could thus rank the stereotypes in terms of prominence according to what percentage of responses cohered within it (for instance, $27.8 \%$ of all codes for men with physical disability (MWPD) fell under the 'withdrawn and dependent' stereotype for men).

We arranged the traits within each stereotype in terms of rank (so, for instance, for MWPD, insecure was the most common trait cited under the 'withdrawn and dependent' stereotype). Finally, we highlighted the five highest ranked traits, independent of stereotype, for MWPD and WWPD.

\section{Results}

\section{Sample}

The sample consisted of 1,990 valid survey responses for the qualitative data. One hundred and twenty-five participants who met the Washington Group criteria for having a disability using standard cut-offs were excluded, so the remaining group were people without disability, according to the Washington Group criteria (Madans, Loeb, \& Altman, 2011). These items measure disability in functional terms, and include questions regarding the respondent's abilities in terms of seeing, hearing, ambulating, cognition, self-care and communication. They have been used in numerous contexts (Altman, 2016; Madans \& Loeb, 2013). The response options range from 1, 'No- no difficulty', to 2, 'Yes- some difficulty', to 3, 'Yes- a lot of difficulty', and, finally, to 4, 'Cannot do at all'. People are considered to have a disability if they score 3 or 4 to any of the questions. Of the remaining 1,865 responses, 1,723 provided valid qualitative data (i.e., did not have missing or nonsensical responses, such as 'fggg'). The mean age was 26 years (SD = 9.15), and ranged from 18 years to 76 years. There were fewer males $(43.3 \%)$ than females (57.7\%). The sample consisted of $42.8 \%$ Black African, $42 \%$ White, $8.9 \%$ 
Coloured, and $4.5 \%$ Asian or Indian people, as well as $1.7 \%$ who self-identified as 'other'. Of the participants, $51.2 \%$ held a school leaving certificate. In South Africa (total population estimated at $54,490,000$ ), $67.5 \%$ of the population identify as Black and only $21.6 \%$ as White. In terms of education, according to the South African Census (Statistics South Africa, 2011), the percentage of people aged 20 or older with a school leaving certificate is $28.5 \%$. Therefore, our sample has a higher number of White participants and is better educated than the general population.

\section{Stereotypes Regarding Men With Physical Disabilities (MWPD)}

In the analysis, the individual traits were clustered into relatively discrete stereotypes. Stereotype prominence was calculated by summing the total prevalence of traits associated with that stereotype. There were seven such stereotypes concerning MWPD. The present section, then, will consider these homogenising images of men with disability first. Thereafter, we list the five most prominent individual traits, independent of the stereotype from which they hail.

The most prominent stereotype was of MWPD as 'withdrawn and dependent'. The top five traits within this stereotype were insecure, shy, weak, dependent, and introverted. The second most prominent stereotype was the 'SuperCrip' - a cluster of traits which positioned MWPD as somehow superhuman, ultra-capable, and heroic. The top five most prevalent traits associated with this stereotype were strong, determined, brave, independent, and intelligent.

The third most prominent stereotype for men was that of a 'nice guy' - an image of a person who was optimistic, kind, happy, and friendly. The top five most prevalent traits associated with this stereotype were friendly, kind, funny, positive, and patient.

Next, in order of total prevalence, was a group of traits which did not indicate a homogenising view of MWPD, but instead cited traits related to the physical impairments which participants associated with MWPD. These included mobilityimpaired, physically limited, blind, hearing-impaired, and visually-impaired. Next, MWPD were often portrayed as 'angry'. The image of thwarted masculinity which this cluster of traits pointed to was salient. The top five most prevalent traits associated 
with this stereotype were frustrated, stubborn, short-tempered, grumpy, and defensive.

The penultimate stereotype concerning MWPD portrayed these men as 'lacking sexuality'. The top five traits associated with this stereotype of the sexual man with a physical disability were impotent, emasculated, unattractive, 'can't perform sexually', and asexual. The last, lowest-scoring category of traits were those which were not strictly traits, but rather the absence of specific characteristics or markers of difference. This category thus included responses such as 'everyone is different', 'same as able-bodied', and 'disability doesn't define a person'.

Of these seven groups of traits, five were counted as stereotypes proper, and two as mere trait clusters (clusters of traits which did not so much create a coherent image of PWPD, but instead reflected types of characteristics associated with them).

Further to the stereotypes proper and trait clusters, and their respective rankings, we also calculated the individual traits in terms of relative frequency. For MWPD, the top five most prevalent individual traits cited were strong, funny, insecure, weak, and determined. When we separated these individual traits by respondent, we found that female participants most commonly called MWPD strong, insecure, determined, shy, friendly, and brave (in that order). Meanwhile, male participants most commonly called MWPD strong, insecure, determined, friendly, weak, and kind (in that order).

\section{Stereotypes Regarding Women With Physical Disabilities (WWPD)}

There were also seven stereotypes concerning WWPD. The most prominent stereotype was of WWPD as withdrawn and dependent. Similar to the same stereotype concerning MWPD, the top five traits associated with this stereotype were insecure, shy, dependent, quiet, and sad (the notable difference being the inclusion of a depressive trait).

As in the case with MWPD, the SuperCrip stereotype ranked second overall for WWPD. Here, the most prevalent traits associated with the female SuperCrip were strong, determined, independent, brave, and courageous. 
The female corollary of the nice guy stereotype concerning MWPD also ranked third in cumulative trait score for women with disabilities. The top five traits associated with this image of WWPD as 'nice ladies' were kind, friendly, positive, intelligent, and caring.

Next, in order of total prevalence, was a group of traits which related to the physical impairments which participants associated with WWPD. The five most prevalent traits were mobility-impaired, blind, hearing-impaired, physically limited, and paralysed.

Next, for women, was a cluster of traits which did not so much point to a stereotype of WWPD, but instead, revealed inclusive attitudes on the part of participants, or were traits indistinguishable from those usually associated with women, regardless of impairment. The top five most prevalent traits in this image of the WWPD were 'everyone-is-different', beautiful, human, normal, and female.

Next, WWPD were portrayed as 'irritable and aloof'. The top five traits in this stereotype were frustrated, short-tempered, unfriendly, aloof, and angry.

The least prominent stereotype concerning WWPD concerned sexuality - that they were sexually undesirable. Unlike men, for whom the sexuality stereotype ranked above that which characterised MWPD as normal, for women, this stereotype was not as desexualising and did not appear as prominent in the minds of participants. The top five traits which were associated with this stereotype were unattractive, ineligible, asexual, 'difficulties with reproduction', and 'bad mothers'.

Of these seven, five were counted as stereotypes proper, and two as trait clusters. Aside from the overall stereotypes, and their respective rankings, we also calculated the individual traits for WWPD in terms of relative frequency. The top five most prevalent individual traits cited were strong, insecure, shy, kind, and friendly.

When we separated these individual traits by respondent gender, we found that female participants most commonly called WWPD strong, shy, insecure, friendly, 
and determined (in that order). Meanwhile, male participants most commonly called WWPD insecure, kind, friendly, strong, shy, and dependent (in that order).

\section{Limitations}

Self-report measures are sensitive to social desirability concerns. Consequently, a largely online and anonymous survey using indirect measures seemed a suitable way to attempt to circumvent social desirability in the present study, insofar as is possible. However, there could have been a priming effect in the present study, as the free-response items were situated near the end of a survey with questions about disability and sexuality, which may have influenced replies. Given that stereotypes concerning sexuality were not very prevalent in the present data set, there does not seem to be much evidence of a priming effect here.

\section{Discussion}

A promising interpretation of our findings is offered by stereotype content model research. Fiske, Cuddy, Glick, and Xu (2002) argued that there are two dimensions organising most group stereotypes: warmth (traits denoting emotional qualities of a group) and competence (traits denoting intellectual/capability qualities of a group). Research has shown that stereotypes are often mixed. When called on to spontaneously describe an Other, we often cite traits which are positive on one of these dimensions and negative on the other (Cuddy, Norton, \& Fiske, 2005; Eckes, 2002; Rohmer \& Louvet, 2012).

In a paper published in 2012, Rohmer and Louvet (2012) noted that such ambivalent stereotype contents are supposed to be due to a conflict between prejudice and societal pressures against prejudice (as seen in the work of, for instance, Judd, James-Hawkins, Yzerbyt, and Kashima (2005)).

Working from the premise that such mixed stereotype content is the result of a compensation process based on social norms, these authors hypothesised that ambivalent stereotype content observed with explicit measures of stereotypes would not manifest itself with implicit measures, as the latter are less affected by social demand characteristics (Rohmer \& Louvet, 2012). As in the case of most low-status groups, PWD (including PWPD) are often rated, by non-disabled people, as high in 
warmth, but given low ratings in competence (Cuddy, Fiske, \& Glick, 2007; Louvet \& Rohmer, 2010).

Seeing PWPD as high in warmth could stem from the motivation to appear unprejudiced by non-disabled people, given that they are actively inclined to rate PWPD as low in competence (Dambrun \& Guimond, 2004; Louvet, Rohmer, \& Dubois, 2009). In their study, Rohmer and Louvet (2012) found that there were discrepancies between responses obtained using implicit and explicit measures, with responses at the explicit level revealing positive and negative stereotype content, and implicit measures revealing consistently negative stereotype content; when nondisabled people are deprived of the capacity to socially moderate and control their responses, their stereotypes of PWD are more likely to be consistently negative. This offers a useful frame for interpreting the general lie of the land of our results. However, it is also worth exploring, in depth, the nature and implications of individual stereotypes.

As in past research, we found marked consistency between stereotypes of PWPD of both genders (Nario-Redmond, 2010). The prominence of overall stereotypes for men and women was the same: withdrawn and dependent, SuperCrip, nice guy/girl, angry/irritable and aloof, and lacking sexuality/sexually undesirable. However, for women, the trait cluster for inclusive or neutral traits, or traits more characteristic of 'ordinary' gender stereotypes, ranked higher overall than this trait cluster did for men. For men, such neutral or inclusive traits were least prevalent. And, for women, the stereotype asexual ranked lowest, whereas for men it ranked second-last (followed by the inclusive or neutral trait cluster). For both genders, the fourth most prominent image of disability was the trait cluster concerned with physical impairment.

Our findings support those of past work which found that MWPD and WWPD are stereotyped in consistent ways across genders (Nario-Redmond, 2010; Schlesinger, 1996; Tilley, 1996). However, while Crawford and Ostrove $(2003,186)$ found that people without disability believed all PWD, including PWPD, to be 'universally intellectually challenged', lacking sexuality, and helpless and incompetent, these traits, aside from helplessness, were not very prominent in the present study. Instead, MWPD and WWPD were seen as strong, funny, insecure, shy, and 
determined, traits which appeared to arise from participants' drawing on stereotypes of MWPD as withdrawn and dependent, SuperCrips, or nice.

It is worth exploring these stereotypes both from a psychodynamic, individual-level perspective, as well as from a more sociological perspective, as both interpretations hold weight.

\section{Withdrawn and dependent}

Concerning the image of PWPD as withdrawn and dependent, it is worth turning to the individual traits cited for possible explanations for the prominence of this stereotype. For men, these traits were insecure, shy, weak, dependent, and introverted; for women, they were insecure, shy, weak, dependent, and introverted. What might be seen to be at play here are a process of projection (psychodynamic), and a process of binary opposition (sociological).

In the first instance, we can see possible evidence for projection. Projection, in psychodynamic terms, is the process by which people defend against their own unconscious impulses or qualities (often those which they find unpleasant) by attributing them to others - for instance, perceiving one's spouse to be angry when one is angry oneself. A critical psychoanalytic view of disablism (Marks, 1999; Watermeyer, 2013) proposes that PWD are 'psychically exploited' (Author \& Author, under review, 2) by the dominant majority, as containers for the projection of unwanted human characteristics such as shame and vulnerability. In the present study, by constructing a stereotypical image of PWPD as weak and dependent, participants may be projecting onto disability all of their fears and fantasies about what it would mean to have a physical impairment, as has been suggested in past work (Shakespeare, 1994). They imagine, perhaps, that they would feel powerless and dependent, and would withdraw.

This projection, however, is not an enactment of the purely imagined. Some PWPD do have substantial care needs. Thus, rather than merely projecting the feared sequelae of disability, and what physical impairment represents, these responses may actually reflect a projective identification with the real care needs of another, as representing something feared and disavowed in the self. Projective identification 
takes projection a step further; the individual does not simply project their disavowed feelings or attributes onto another, but actually strives to induce those feelings or attributes in another (in the example earlier, actively acting in a manner which will likely anger one's spouse in order to validate one's perception of them as angry). Projective identification could lead non-disabled people to actively seek out the dependency, for instance, which they fear in their selves and project onto PWPD, and foster it amongst PWPD whom they encounter.

In the second, sociological interpretation, these traits point to the opposite of the 'ideal of able-bodiedness': if we can conceive, as Garland-Thomson (1997) does, of a non-disabled norm against which the disabled other is constructed, then what we have here is evidence of this process in relation to an image of people without disability as secure, outgoing, strong, independent, and extroverted. If these can be considered the hallmarks of ability and success, we can see how participants may be aware of social constructions of disability in opposition to this ideal. Such images are perpetuated in charity advertising (Grue, 2016).

Taken together, though, it seems that participants are drawing on images of PWPD circulating in popular consciousness. As Schneider (2005) notes, consistency amongst individual views and beliefs about a group of people will reveal the nature of cultural stereotypes. We found such consistency, and thus evidence of a cultural stereotype. Whether this stereotype leads to the citing of the traits we found, or if the process of binary opposition and projection leads to the formation of a stereotype, is not possible to ascertain here - in fact, it is likely a synergistic effect of both together, the one mirroring on the social level (binary opposition), the other (projection). However, what is interesting to note is that the presence of this stereotype does reflect a certain construction of disability which bears little resemblance to constructions of the capable normate.

\section{SuperCrip}

In terms of the SuperCrip stereotype, there are, again, two interpretations - one psychodynamic, and one sociological. Considering the first, Watermeyer (2009, 2013) proposes that the SuperCrip stereotype epitomises the imperative of being 'un-disabled' - a form of enforcing 'compulsory able-bodiedness' (McRuer, 2010). 
Author and Author (under review) note that the media phenomenon of the 'supercrip' is an extreme instantiation of stoic reassurance. In this process, PWPD perform stoicism in order to prove their capacity to resist or contain others' projections. PWPD may take on superhuman tasks, purportedly in an effort to disprove denigrating stereotypes. In so doing, they become part of a media machine which perpetuates stereotypes of PWPD as needing to perform exceptional tasks in order to qualify as 'able-bodied enough'.

However, on a broader level, certain contextual interpretations of this finding can be made. South Africa's most famous disabled person is the athlete Oscar Pistorius, who has been the subject of both idealising and extremely denigrating media attention, especially after he killed his girlfriend. There was, for example, a temporary television channel devoted solely to Pistorius' murder trial. For this reason, the SuperCrip image (with all its ambiguities) may be especially accessible for South Africans. The SuperCrip image may be even more salient in South Africa, where disability and PWD are more hidden from view than in countries where there are higher degrees of integration of PWD (Stadler, 2006).

\section{Nice guy/Nice lady}

The prominence of traits associated with a 'nice guy' or 'nice lady' PWPD provides evidence for the sort of enforcement of happiness and humour on PWPD of which past authors have written (Shakespeare, 1999). Ascribing traits such as friendly, kind, funny, positive, caring and patient to PWPD could be evidence of people without disability's reference to an over-compensatory standard of self-presentation to which PWPD often feel themselves held. Media and other portrayals of disability often portray PWD as cheerful and easy going - somehow compensating with congenial personalities for what they lack physically, or simply protecting people without disability from difficulties associated with physical impairment which the latter may find off-putting.

Author and Author (under review), as well as Watermeyer $(2009,2013)$, reflect on the creation (or, in this case, enforcement) of a persona of easy-goingness on PWPD to the imperative of being 'un-disabled'. PWPD need to - must be - cheerful 
and happy in order to reassure non-disabled people that their needs and difference are manageable and not threatening.

However, reference to these positive traits may also reflect inclusive attitudes towards PWPD. By ascribing positive traits to PWPD, participants may simply be indicating positive attitudes towards PWPD. This interpretation is supported from findings from the same sample which found inclusive attitudes towards dating PWPD (see Author et al., 2018).

\section{Gender}

Finally, we need to consider what our findings mean for thinking about gender and disability, precisely because gender did not appear as an important axis of stereotyping in the present study. In the introduction to this paper, we noted that problematic attitudes towards PWPD, particularly as pertains to their gender, sexuality, and suitability as romantic partners, are prevalent, and that some of this appears to be due to negative social constructions and stereotypes concerning PWPD.

Drawing on Schlesinger's (1996) assertion that disability disrupts traditional ideologies regarding gender identity, we noted that past work has found that common stereotypes relating to MWPD and WWPD are constructed in opposition to the traditional gender characteristics of men and women (Tilley, 1996).

In our study, we found some evidence that stereotypes of MWPD are constructed in opposition to male gender identity, where the latter is traditionally constructed around notions of sexual prowess, physicality and productivity. MWPD were seen as strong, funny, insecure, shy, and determined. Although strength is stereotypically associated with men, the fact that participants also cited this trait in relation to WWPD points to the fact that it was not activated in relation to an underlying gender stereotype for men, but rather an underlying stereotype for PWPD.

We failed to find evidence that stereotypes of WWPD are constructed in opposition to those normally associated with women: women with disabilities were conceived of 
as strong, insecure, shy, kind, and friendly in our study, and none of these attributes are particularly at odds with stereotypes of femininity.

However, it is important to note that for neither WWPD nor MWPD were the top cited traits particularly masculine nor particularly feminine. Instead, they seem to reflect gender-neutral disability stereotypes. This provides evidence, we argue, that disability trumps gender in terms of salience in stereotype activation: people without disability are likely to stereotype PWPD according to their disability status prior to their gender. This supports Rich's (2014) assertion that disability is a primary hallmark of identity: an identity which supersedes gender.

Finally, recalling the work cited in the beginning of this paper, which proposed that the intersection of gender and disability stereotypes has particularly dire consequences for women with disabilities, as they are seen as lacking sexuality, virgins, sexually overactive, cursed, dirty or clean, we did not find these traits to be prominently associated with WWPD. This stems from the fact that sexuality traits constituted a small proportion of the overall traits cited for PWPD in this study.

However, the following two important points are worthy of further consideration in research. Firstly, the stereotypes concerning PWPD's sexuality for women was less prevalent than its counterpart for men $(2.04 \%$ versus $5 \%$ of all traits cited). This, perhaps ominously, points to the fact that physical disability is not seen as a barrier to sex (conceived of narrowly as penetrative heterosexual sex) for WWPD, as it is with men. Although apparently positive, this may also point towards a problematic understanding of what it means to be sexual, and also reinforces the idea that women can be passive recipients of sex, rather than active participants; if participants think that a state of being would disqualify men from participating in sexual activity, but not women, then what does this say about their understandings of the rules of engagement in the sexual act?

Secondly, if we do reflect on the traits included in the sexuality stereotype for women (unattractive, ineligible, asexual, difficulties with reproduction, and bad mothers), we can readily see why these may have negative consequences for WWPD (they also portray these women as undesirable partners, rather than as lacking sexuality). They 
may not be prominent, but they are highly problematic. With rates of sexual violence against women in the country being as high as they are, stereotypes of WWPD which portray them as unlikely sexual partners may work, as Hanass-Hancock $(2009,40)$ suggests, to make them likely targets of such violence: 'sexual abuse or exploitation was sometimes interpreted as a blessing such as that the person with disability can "count herself lucky" to have sexual intercourse'.

\section{Conclusions}

Although we found marked incongruity at the individual level between non-disabled people's ascription of traits to PWPD, we found evidence of the consistency amongst our sample's views and beliefs about a target group which Schneider (2005) asserts to be evidence of stereotypes.

The most prominent stereotypes in the present study were those which characterised PWPD as withdrawn and shy, SuperCrips, or happy, funny, and kind. These stereotypes can be read in both psychological and sociological terms, but regardless of origin or function - seem to be extremely similar between genders of PWPD.

We proposed that it is relevant to examine societal stereotypes concerning MWPD and WWPD: stereotypes are likely to be desexualising or at least de-gendering for PWPD; stereotypes guide attitudes; and such attitudes, when encountered by PWPD, are harmful.

The findings in the present paper suggest that stereotypes of PWPD are not overwhelmingly de-sexualising, but are undifferentiated by gender. The latter point seems to evince a de-gendering of PWPD by people without disability. It would appear, then, that - as proposed by Rich (2014) - disability does trump gender in the eyes of non-disabled people, when it comes to primacy of identity: stereotypes in our study were activated primarily in reaction to disability, and latterly in relation to gender, when it came to men and women with disabilities. However, when examined specifically, we did find evidence of stereotypes regarding physical disability and femininity which could place WWPD at risk of negative attitudes, and even, as Hanass-Hancock (2009) proposes, sexual violence. 


\section{Funding}

The financial assistance of the International Foundation of Applied Disability Research (FIRAH) and the National Research Foundation (NRF) of South Africa is hereby acknowledged. Opinions expressed and conclusions arrived at are those of the authors and are not necessarily to be attributed to FIRAH or the NRF.

\section{Conflict of interest}

No conflict of interest.

\section{References}

Author et al. (2018).

Author et al. (under review). Navigating the relational psychic economy of disability.

Abrams, D., Jackson, D., \& St. Claire, L. (1990). Social identity and the handicapping functions of stereotypes: Children's understanding of mental and physical handicap. Human Relations, 43(11), 1085-1098.

Altman, B. M. (Ed.). (2016). International measurement of disability. Springer.

Asch, A., \& McCarthy, H. (2003). Infusing disability issues into the psychology curriculum. In P. Bronstein \& K. Quina (Eds.), Teaching gender and multicultural awareness: Resources for the psychology classroom (pp. 253269). Washington, DC, US: American Psychological Association. http://dx.doi.org/10.1037/10570-018

Ashmore, R. D., \& Del Boca, F. K. (1981). Conceptual approaches to stereotypes and stereotyping. Cognitive Processes in Stereotyping and Intergroup Behavior, 1, 35.

Banks, M. E. (2010). Feminist psychology and women with disabilities: An emerging alliance. Psychology of Women Quarterly, 34(4), 431-442.

Bargh, J. A. (1999). The cognitive monster: The case against the controllability of automatic stereotype effects. In S. Chaiken \& Y. Trope (Eds.), Dual-process theories in social psychology (pp. 361-382). New York, NY, US: Guilford Press.

Braathen, S. H., \& Ingstad, B. (2006). Albinism in Malawi: knowledge and beliefs from an African setting. Disability \& Society, 21(6), 599-611. 
Coleman, J. M., Brunell, A. B., \& Haugen, I. M. (2015). Multiple forms of prejudice: How gender and disability stereotypes influence judgments of disabled women and men. Current Psychology, 34(1), 177-189.

Condrau, F. (2007). The patient's view meets the clinical gaze. Social History of Medicine, 20(3), 525-540.

Crawford, D., \& Ostrove, J. M. (2003). Representations of disability and the interpersonal relationships of women with disabilities. Women \& Therapy, 26(3-4), 179-194.

Cuddy, A. J., Fiske, S. T., \& Glick, P. (2007). The BIAS map: behaviors from intergroup affect and stereotypes. Journal of Personality and Social Psychology, 92(4), 631.

Cuddy, A. J., Norton, M. I., \& Fiske, S. T. (2005). This old stereotype: The pervasiveness and persistence of the elderly stereotype. Journal of Social Issues, 61(2), 267-285.

Dambrun, M., \& Guimond, S. (2004). Implicit and explicit measures of prejudice and stereotyping: Do they assess the same underlying knowledge structure? European Journal of Social Psychology, 34(6), 663-676.

Dixon, J. (2017). 'Thinking ill of others without sufficient warrant?' Transcending the accuracy-inaccuracy dualism in prejudice and stereotyping research. British Journal of Social Psychology, 56(1), 4-27. doi:10.1111/bjso.12181.

Eckes, T. (2002). Paternalistic and envious gender stereotypes: Testing predictions from the stereotype content model. Sex Roles, 47(3-4), 99-114.

Fiske, S. T., Cuddy, A. J., Glick, P., \& Xu, J. (2002). A model of (often mixed) stereotype content: competence and warmth respectively follow from perceived status and competition. Journal of Personality and Social Psychology, 82(6), 878.

Foddy, M., Platow, M. J., \& Yamagishi, T. (2009). Group-based trust in strangers: The role of stereotypes and expectations. Psychological Science, 20(4), 419422.

Garland-Thomson, R. (1997). Feminist theory, the body, and the disabled figure. In

L. Davis (Ed.), The disability studies reader (pp. 279-292). Routledge.

Garland-Thomson, R. (2009). Staring: How we look: Oxford University Press.

Goffman, E. (1959). The presentation of self in everyday life. New York, NY: Doubleday. 
Government of United Kingdom. (2010). National Equality Act. Retrieved from https://www.legislation.gov.uk/ukpga/2010/15/contents

Grue, J. (2016). The problem with inspiration porn: a tentative definition and a provisional critique. Disability \& Society, 31(6), 838-849.

Hanass-Hancock, J. (2009). Interweaving conceptualizations of gender and disability in the context of vulnerability to HIV/AIDS in KwaZulu-Natal, South Africa. Sexuality and Disability, 27(1), 35-47.

Hergenrather, K., \& Rhodes, S. (2007). Exploring undergraduate student attitudes toward persons with disabilities: Application of the disability social relationship scale. Rehabilitation Counseling Bulletin, 50(2), 66-75.

Hubbard, P. (1998). Sexuality, immorality and the city: red-light districts and the marginalisation of female street prostitutes. Gender, Place and Culture: $A$ Journal of Feminist Geography, 5(1), 55-76.

Judd, C. M., James-Hawkins, L., Yzerbyt, V., \& Kashima, Y. (2005). Fundamental dimensions of social judgment: understanding the relations between judgments of competence and warmth. Journal of Personality and Social Psychology, 89(6), 899.

Kao, G. (2000). Group images and possible selves among adolescents: Linking stereotypes to expectations by race and ethnicity. Sociological Forum, 15(3), 407-430.

Kvam, M. H., \& Braathen, S. H. (2008). "I thought...maybe this is my chance." Sexual abuse against girls and women with disabilities in Malawi. Sexual Abuse, 20(1), 5-24.

Louvet, E., \& Rohmer, O. (2010). Les travailleurs handicapés sont-ils perçus comme des travailleurs compétents? Psychologie du Travail et des Organisations, 16(1), 47-62.

Louvet, E., Rohmer, O., \& Dubois, N. (2009). Social judgment of people with a disability in the workplace: How to make a good impression on employers. Swiss Journal of Psychology, 68(3), 153-159.

Madans, J. H., \& Loeb, M. (2013). Methods to improve international comparability of census and survey measures of disability. Disability and Rehabilitation, 35(13), 1070-1073.

Madans, J. H., Loeb, M. E., \& Altman, B. M. (2011). Measuring disability and monitoring the UN Convention on the Rights of Persons with Disabilities: the 
work of the Washington Group on Disability Statistics. BMC Public Health, 11(4), S4.

Manthorpe, J., Bowes, A., Innes, A., Archibald, C., \& Murphy, C. (2004). Dementia and social inclusion: Marginalised groups and marginalised areas of dementia research, care and practice. Jessica Kingsley Publishers.

Maras, P., \& Brown, R. (1996). Effects of contact on children's attitudes toward disability: A longitudinal study. Journal of Applied Social Psychology, 26(23), 2113-2134.

Marini, I., Chan, R., Feist, A., \& Flores-Torres, L. (2011). Student attitudes toward intimacy with persons who are wheelchair users. Rehabilitation Research, Policy, and Education, 25(1-2), 15-25.

Marks, D. (1999). Disability: Controversial debates and psychosocial perspectives. Psychology Press.

McCauley, C., \& Stitt, C. L. (1978). An individual and quantitative measure of stereotypes. Journal of Personality and Social Psychology, 36, 929-940.

McRuer, R. (2010). Compulsory able-bodiedness and queer/disabled existence. In L. Davis (Ed.), The disability studies reader (pp. 383-392). Routledge.

Miller, E., Chen, R., Glover-Graf, N. M., \& Kranz, P. (2009). Willingness to engage in personal relationships with persons with disabilities examining category and severity of disability. Rehabilitation Counseling Bulletin, 52(4), 211-224.

Nario-Redmond, M. R. (2010). Cultural stereotypes of disabled and non-disabled men and women: Consensus for global category representations and diagnostic domains. British Journal of Social Psychology, 49(3), 471-488.

Nguyen, T. T. A., Liamputtong, P., \& Monfries, M. (2016). Reproductive and sexual health of people with physical disabilities: a metasynthesis. Sexuality and Disability, 34(1), 3-26.

Niemann, Y. F., Jennings, L., Rozelle, R. M., Baxter, J. C., \& Sullivan, E. (1994). Use of free responses and cluster analysis to determine stereotypes of eight groups. Personality and Social Psychology Bulletin, 20(4), 379-390.

Reeve, D. (2012). Psycho-emotional disablism in the lives of people experiencing mental distress. In J. Anderson, B. Sapey, \& H. Spandler (Eds.), Distress or disability? (pp. 24-29). Proceedings of a symposium held at Lancaster Disability 15-16 November 2011, Lancaster: Centre for Disability Research, Lancaster University. 
Rich, K. (2014). "My body came between us": accounts of partner-abused women with physical disabilities. Affilia, 29(4), 418-433.

Rohmer, O., \& Louvet, E. (2012). Implicit measures of the stereotype content associated with disability. British Journal of Social Psychology, 51(4), 732740.

Schlesinger, L. (1996). Chronic pain, intimacy, and sexuality: A qualitative study of women who live with pain. Journal of Sex Research, 33(3), 249-256.

Schneider, D. J. (2005). The psychology of stereotyping. Guilford Press.

Sechrist, G. B., \& Stangor, C. (2001). Perceived consensus influences intergroup behaviour and stereotype accessibility. Journal of Personality and Social Psychology, 80(4), 645.

Shakespeare, T. (1994). Cultural representation of disabled people: dustbins for disavowal? Disability \& Society, 9(3), 283-299.

Shakespeare, T. (1999). Joking a part. Body \& Society, 5(4), 47-52.

Statistics South Africa. (2011). South African National Census of 2011. Pretoria:

Statistics South Africa. Retrieved from

https://www.statssa.gov.za/publications/P03014/P030142011.pdf

Stadler, J. (2006). Media and disability. In B. Watermeyer, L. Swartz, T. Lorenzo, M. Schneider, \& M. Priestley (Eds.), Disability and social change: A South African agenda (pp. 373-386). South Africa: Human Sciences Research Council Press.

Tiedens, L. Z., Ellsworth, P. C., \& Mesquita, B. (2000). Sentimental stereotypes: Emotional expectations for high-and low-status group members. Personality and Social Psychology Bulletin, 26(5), 560-575.

Tilley, C. M. (1996). Sexuality in women with physical disabilities: A social justice or health issue? Sexuality and Disability, 14(2), 139-151.

Watermeyer, B. (2013). Towards a contextual psychology of disablism. Routledge. 